\title{
Distribuição Espaço-Temporal e Sazonalidade das Chuvas no Estado do Mato Grosso
}

\author{
Francisco F. N. Marcuzzo, Denise C. R. Melo \\ Companhia de Pesquisa de Recursos Minerais / Serviço Geológico do Brasil - CPRM/SGB \\ francisco.marcuzzo@cprm.gov.br; denise.melo@cprm.gov.br \\ Hudson M. Rocha \\ Departamento de Geografia - Universidade Federal de Goiás - UFG \\ sauhudson@gmail.com
}

Recebido: 21/07/10 - revisado: 30/01/11 - aceito: 24/08/11

\begin{abstract}
RESUMO
A análise do comportamento das chuvas se torna importante, uma vez que possibilita detectar tendências ou alterações no clima, em escalas locais ou regionais. O presente trabalho teve como objetivo analisar a variação espacial, temporal e sazonal da precipitação pluvial no estado do Mato Grosso. Utilizaram-se dados de 75 estações pluviométricas distribuídas no estado do Mato Grosso, com dados de 30 anos, de 1977 a 2006. Foram elaborados mapas de chuvas com o auxílio de isoietas e aplicado o cálculo do Índice de Anomalia de Chuva (IAC) para a classificação dos períodos secos e úmidos, de acordo com a média local, organizadas em médias temporais mensal, anual e sazonal da precipitação. O método de interpolação utilizado foi o Topo to Raster, na qual utiliza o método multi-grid simples para minimizar a equação em resoluções cada vez melhores, respeitando restrições dos elementos físicos que compõem a paisagem. Os resultados mostram que a distribuição pluviométrica no estado do Mato Grosso apresenta uma grande variação nos índices precipitados, sendo as localidades que situam no extremo noroeste e norte com os maiores valores de chuvas e as localidades situadas ao sul do estado com os menores índices pluviais. Na aplicação do IAC para o período de estudo pode-se verificar que há um maior número de anos secos que anos úmidos.
\end{abstract}

Palavras-chave: Precipitação pluviométrica, pluviometria, Índice de Anomalia de Chuva.

\section{INTRODUCÃ̃O}

A utilização do Sistema de Informação Geográfica (SIG) tem sido de fundamental importância na representação espacial e temporal dos estudos de distribuição de chuvas, porque permite uma boa aproximação da realidade climática da área estudada. Braz et al. (2009), em estudo utilizando o SIG para verificar a distribuição temporal e espacial das chuvas na Bacia Barra Seca (ES), e três métodos matemáticos, que foram a média aritmética, polígonos de Thiessen e Interpolação - Inverso da Distância (IDW), concluiu que apesar de apresentarem resultados semelhantes, é sugerida a utilização do interpolador IDW para representação da distribuição das chuvas, devido a produção de mapas contínuos e heterogêneos.

Em um estudo dos padrões da distribuição espacial da chuva de 60 postos pluviométricos no território de Israel, Gai et al. (1998) observaram nos registros alterações nos padrões pluviométricos com valores superiores da distribuição estatística esperada. Os autores também observaram eventos extremos com acentuada freqüência, revelando, ao sul do território de Israel, impactos relativos, como o recuo de áreas áridas.

Silva et al. (2003) utilizando cálculos estatísticos como: média aritmética, desvio-padrão, valores máximos e valores mínimos, além de histogramas, para o estudo da variabilidade temporal da precipitação mensal e anual, para a estação climatológica de Uberaba-MG, no período de 1914 a 2000, verificou uma normalidade estatística nos meses de outubro a março e assimetria, em relação a média, no período de abril a setembro.

O estado do Mato Grosso, como os demais estados brasileiros, apresenta peculiaridades físicas, como vegetação, relevo e solos, além do posicionamento geográfico, que influenciam diretamente na distribuição das chuvas. Segundo Coutinho (2005), em estudo de verificação da dinâmica das queima- 
das do estado de Mato Grosso, há três grandes macro unidades climáticas da região, que seriam: a) Clima Equatorial Continental Úmido, com estação seca definida da depressão sul Amazônica, ocorrendo na porção norte do estado do Mato Grosso, e elevado excedente hídrico - superior a $1.000 \mathrm{~mm}$; b) Clima Sub-Equatorial Continental Úmido com estação seca definida do Planalto dos Parecis, onde ocorrem valores de precipitação entre 300 a $350 \mathrm{~mm}$; c) Clima Tropical Continental Alternadamente Úmido e Seco das chapadas, planaltos e depressões do Mato Grosso, cujos diferentes níveis de altitude variam de 400 a 800 metros, influenciando diretamente nos valores das chuvas.

Rosa et al. (2007), ao analisarem a distribuição e variabilidade pluviométrica anual na porção centro-oeste do estado de Mato grosso, entre os anos de 1985 a 1995, com a espacialização da chuvas em mapas de isoietas, identificaram que a variabilidade pluviométrica foi irregular, sendo que as chuvas ocorreram em maior quantidade nas porções oeste e sul, e menores quantidades chuvosas registraram-se nas porções leste e norte. Ainda, o autor relata que nos municípios Nobres e Diamantino, nos anos de 1994 e 1995, ocorreram os maiores valores de precipitação, $2800 \mathrm{~mm}$.

Oliveira et al. (2007) estudaram o comportamento temporal da precipitação na região sudeste do estado de Mato Grosso, entre o período de 1982 a 1999, através da análise e tratamento estatísticos dos dados chuvas. Estes autores, por meio de variogramas, verificaram que a precipitação acima de 30 $\mathrm{mm}$, pela análise de chuva por decêndio, ocorreram nos meses de outubro a abril e, menor de $30 \mathrm{~mm}$, no período de maio a setembro.

Dentre os vários métodos estatísticos utilizados em estudos de precipitação pluviométrica, o Índice de Anomalia de Chuva (IAC) se destaca, por permitir o acompanhamento climático com comparações entre as condições atuais e os valores históricos de chuvas, e também para o entendimento da distribuição espacial e temporal entre períodos os secos e úmidos. Assim, sabendo-se do IAC, órgãos governamentais ou entidades privadas podem utilizar de forma sustentável os recursos naturais, como por exemplo, para o zoneamento agrícola ou o planejamento regional, uma vez que há um conhecimento parcial da dinâmica da chuva.

Araújo et al. (2009) utilizando IAC em estudo da bacia do rio Paraíba/PB, verificou que a variação temporal do IAC dos anos secos de 1987 e 1990 é condizente com regime pluviométrico da região, sendo que nos períodos úmidos de 1984 a distribuição do IAC é irregular, principalmente na estação chuvosa. Já à variação espacial do IAC dos anos secos de 1987 e 1990, demonstrou índices que variam de seco a extremamente seco, principalmente no ano de 1990, sobre a influência do El Niño na região.

Conforme as abordagens descritas acima, este trabalho tem como objetivo analisar a variação espacial, temporal e sazonal da precipitação pluvial no estado do Mato Grosso, utilizando séries históricas de chuvas e o cálculo estatístico do IAC, para aferir qualitativamente os dados utilizados.

\section{MATERIAL E MÉTODOS}

\section{Caracterização da área de estudo}

O estado do Mato Grosso está localizado na Região centro-oeste do Brasil, possui uma área de $903.357,908 \mathrm{~km}^{2}$, limita-se entre os paralelos $8^{\circ}$ a $19^{\circ}$ sul e os meridianos $51^{\circ}$ a $62^{\circ}$ oeste (Figura 1 ). O Mato Grosso possui 142 municípios, agrupados em 22 microrregiões político-administrativas, que fazem parte de 5 mesorregiões (IBGE, 2009). A cobertura vegetal do estado confere três biomas: Cerrado, Pantanal e Floresta Amazônica.

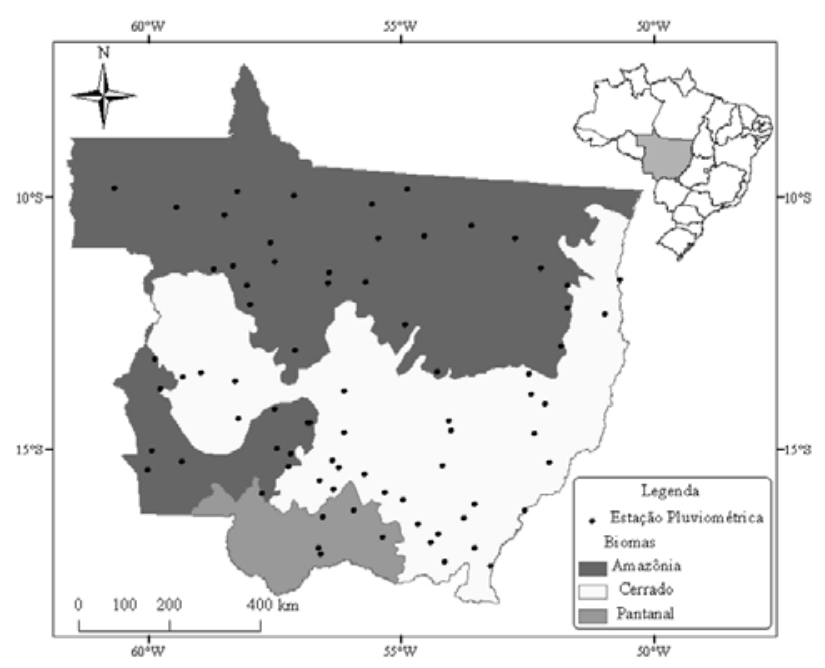

Figura 1 - Localização das estações pluviométricas com 30 anos de dados e os biomas no estado do Mato Grosso.

Os principais mecanismos atmosféricos que atuam em Mato Grosso são as massas de ar equatorial continental e polar atlântica. A massa de ar equatorial, presente entre na primavera e verão, advinda do efeito térmico e da elevada umidade, se desloca para o interior do país no sentido noroeste para 
sudeste, provocando chuvas. A massa polar atlântica é caracterizada pelo acúmulo do ar polar, que atua com maior freqüência no inverno, no sentido sulnorte, favorecendo as quedas de temperatura e estiagem (Nimer, 1989).

\section{Dados utilizados}

Os dados diários de precipitação pluvial utilizados foram obtidos de estações pluviométricas da Rede Hidrometeorológica Nacional da Agência Nacional de Águas (ANA).

Foram utilizados dados de 75 estações pluviométricas distribuídas no estado do Mato Grosso (Figura 1), com 30 anos de dados (1977 a 2006), sendo 37 estações inseridas no bioma da floresta amazônica, 33 no bioma do cerrado e 5 no bioma do pantanal. Os dados pluviométricos foram compilados, consistidos, organizados e tratados estatisticamente, em planilhas eletrônicas, com informação diária, mensal, anual e sazonal, para o posterior mapeamento espacial.

\section{Verificação estatística de anomalias de chuva}

Para a classificação dos períodos secos ou úmidos, de acordo com a média local, foram calculadas as médias temporais mensal, anual e sazonal de precipitação, para o período em estudo, necessárias para o cálculo do Índice de Anomalia de Chuva (IAC) (Quadro 1). Assim, utilizou-se neste trabalho o IAC desenvolvido e testado por Rooy (1965), o qual é calculado pelas seguintes equações:

$\mathrm{IAC}=3\left[\frac{(\mathrm{N}-\overline{\mathrm{N}})}{(\overline{\mathrm{M}}-\overline{\mathrm{N}})}\right]$, para anomalias positivas

IAC $=-3\left[\frac{(\mathrm{N}-\overline{\mathrm{N}})}{(\overline{\mathrm{X}}-\overline{\mathrm{N}})}\right]$, para anomalias negativas

em que,N é a precipitação mensal atual (mm.mês ${ }^{-1}$ ); $\bar{N}$ é a precipitação média mensal da série histórica (mm.mês $\left.{ }^{-1}\right) ; \bar{M}$ é a média das dez maiores precipitações mensais da série histórica $\left(\mathrm{mm} . \mathrm{mês}^{-1}\right)$ e $\bar{X}$ é a média das dez menores precipitações mensais da série histórica (mm.mês ${ }^{-1}$ ).
Quadro 1 - Classificação da pluviosidade segundo o IAC.

\begin{tabular}{|l|l|}
\hline \hline $\begin{array}{l}\text { Índice de Anomalia de } \\
\text { Chuva (IAC) }\end{array}$ & $\begin{array}{l}\text { Classificação da Pluvio- } \\
\text { sidade }\end{array}$ \\
\hline \hline $\mathrm{X}>4$ & Extremamente Chuvoso \\
\hline $\mathrm{X}<2$ e $\mathrm{X}<4$ & Muito Chuvoso \\
\hline $\mathrm{X}>0$ e $\mathrm{X}<2$ & Chuvoso \\
\hline 0 & Nem Chuvoso Nem Seco \\
\hline $\mathrm{X}<0$ e $\mathrm{X}>-2$ & Seco \\
\hline $\mathrm{X}<-2$ e $\mathrm{X}>-4$ & Muito Seco \\
\hline $\mathrm{X}<-4$ & Extremamente Seco \\
\hline \hline
\end{tabular}

\section{Interpolação matemática}

A função Topo to Raster é um método de interpolação baseado no programa ANUDEM desenvolvido por Hutschinson, que foi especificamente feito para a criação de Modelos de Elevação Digital (DEM) hidrologicamente corretos.

O programa interpola os dados de elevação em uma grade regular, de modo iterativo, gerando grades sucessivamente menores, minimizando a rugosidade (roughness penalty) e a soma dos quadrados dos resíduos (diferenças das elevações medidas e calculadas pela função).

Cada elevação em um local é dada por:

$\mathrm{Z}_{\mathrm{i}}=\mathrm{f}\left(\mathrm{x}_{\mathrm{i}}, \mathrm{y}_{\mathrm{i}}\right)+\mathrm{w}_{\mathrm{i}} \varepsilon_{\mathrm{i}}$

em que, $f(x, y)$ é a função de interpolação, definida por uma função B-spline, cada $\mathrm{w}_{\mathrm{i}}$ é uma constante positiva que representa o erro de discretização do ponto i e cada $\varepsilon_{\mathrm{i}}$ é uma amostra de uma variável aleatória, com média zero e desvio padrão igual a um.

Assumindo que cada ponto está localizado aleatoriamente dentro da célula do modelo, a constante $\mathrm{w}_{\mathrm{i}}$ é definida por:

$\mathrm{w}_{\mathrm{i}}=\mathrm{hs}_{\mathrm{i}} / \sqrt{12}$

$\sum_{I=1}^{N}\left[\left(Z_{i}-f\left(x_{i}, y_{i}\right) / w_{i}\right)\right]+\lambda J(f)$

em que, h é o espaçamento da grade; si é a medida de inclinação da célula da grade associada com o ponto $\left(\mathrm{x}_{\mathrm{i}}, \mathrm{y}_{\mathrm{i}}\right)$. A função $\mathrm{f}(\mathrm{x}, \mathrm{y})$ é então estimada resolvendo uma aproximação na grade regular via método das diferenças finitas que minimiza a somatória. A constante $\mathrm{w}_{\mathrm{i}}$ varia com cada iteração, em uma característica adaptativa local (locally adaptive featu- 
re), já que a cada iteração do programa um novo valor de inclinação (si) é disponibilizado para cada célula da grade, conforme o método iterativo avança. Foi utilizado o método multi-grid simples para minimizar a equação em resoluções cada vez melhores, começando de uma grade inicial larga até uma grade que tenha resolução definida pelo usuário, respeitando restrições que garantem a estrutura de drenagem.

\section{RESULTADOS E DISCUSSÃO}

\section{Distribuição dos valores pluviométricos}

A distribuição dos valores pluviais das médias mensal e anual, com base nos dados da série histórica de 1977 a 2006, registradas em 75 estações pluviométricas distribuídos na área em estudo, apresenta uma variação significativa da precipitação.

As Figuras 2 e 3 apresentam as precipitações pluviométricas médias mensais dos meses de janeiro e fevereiro, que compõem o período chuvoso do estado.

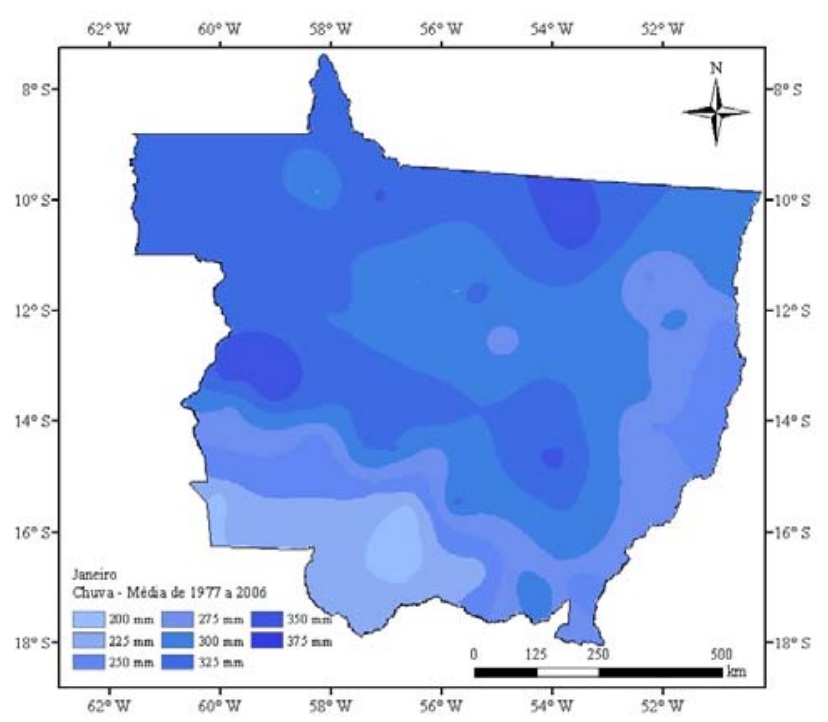

Figura 2 - Precipitação do mês de janeiro.

Os maiores índices pluviais do mês de janeiro (Figura 2) variaram entre 325 a $375 \mathrm{~mm}$, e de 330 a $360 \mathrm{~mm}$ para o mês de fevereiro, ocorrendo nas localidades extremo norte e noroeste áreas com o bioma Amazônico.

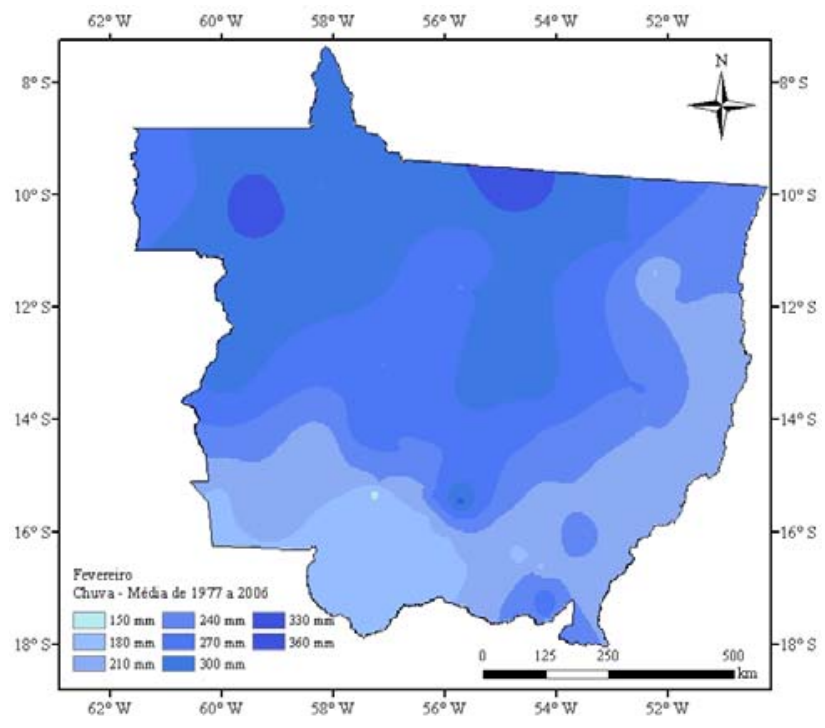

Figura 3 - Precipitação do mês de fevereiro.

Os índices médios pluviais de 275 a $300 \mathrm{~mm}$ (janeiro) e 210 a $270 \mathrm{~mm}$ (fevereiro) ocorreram ao centro do estado, no bioma Cerrado. Já os índices menores pluviométricos tiveram sua ocorrência no bioma pantanal, 200 a $225 \mathrm{~mm}$ no mês de janeiro, e 150 a $180 \mathrm{~mm}$ em fevereiro, na porção sul do estado. Verifica-se assim, que os meses de janeiro e fevereiro apresentaram médias pluviométricas superiores a $150 \mathrm{~mm}$, média do período chuvoso, com tendência a aumento dos índices pluviais no sentindo sul (Pantanal) para o norte (Amazônia) do estado, sendo a massa de ar Equatorial Continental o principal mecanismo atmosférico, que atua na formação de chuva.

Na Figura 4, que apresenta a precipitação pluviométrica média mensal do mês de março, pode-se perceber um enfraquecimento da atuação da massa de ar Equatorial continental e conseqüentemente a diminuição dos valores médios pluviométricos, variando entre 140 a $336 \mathrm{~mm}$. Os índices pluviométricos mais elevados ocorrem ao norte do estado, 280 a $336 \mathrm{~mm}$, coincidindo com o bioma amazônico, e os menores no bioma Pantanal, de 140 a $168 \mathrm{~mm}$. Já os índices médios de precipitação, de 168 a 252 mm, ocorreram no bioma Cerrado, com maior variação dos valores e apresentando a formação de pequenos epicentros pluviométricos.

O mês de abril, apresentado na Figura 5, é período de transição da estação chuvoso para a estação seca, caracterizado pelo enfraquecimento da atuação da massa de ar Equatorial Continental e maior freqüência da massa de ar Polar. Verifica-se um decréscimo dos índices pluviométricos, variando 
de 50 a $225 \mathrm{~mm}$. Os índices mais elevados de precipitação ocorreram no bioma amazônico, de 200 a $225 \mathrm{~mm}$, e os menores, de 50 a $75 \mathrm{~mm}$, no bioma pantanal e a leste do estado.

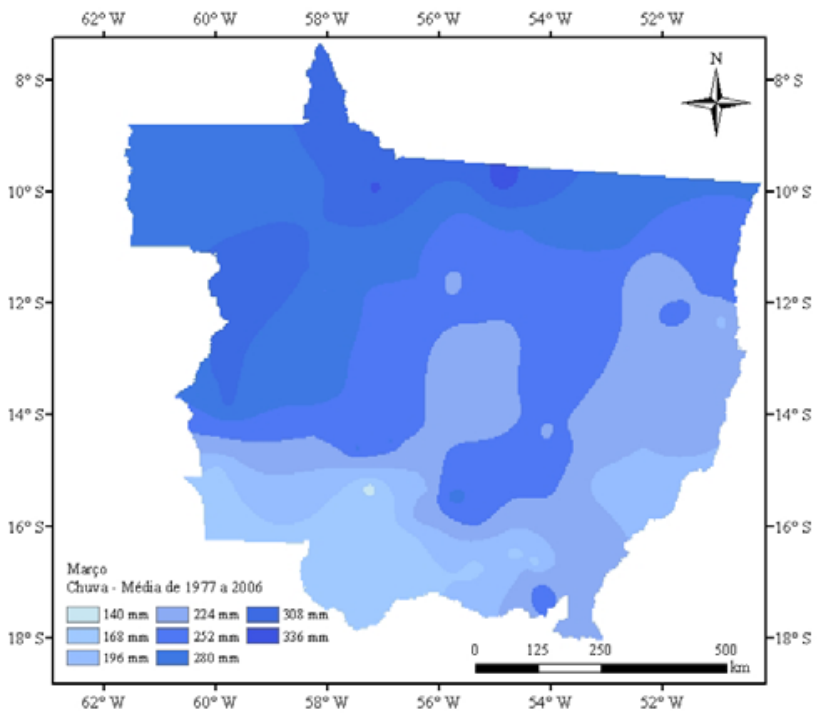

Figura 4 - Precipitação do mês de março.

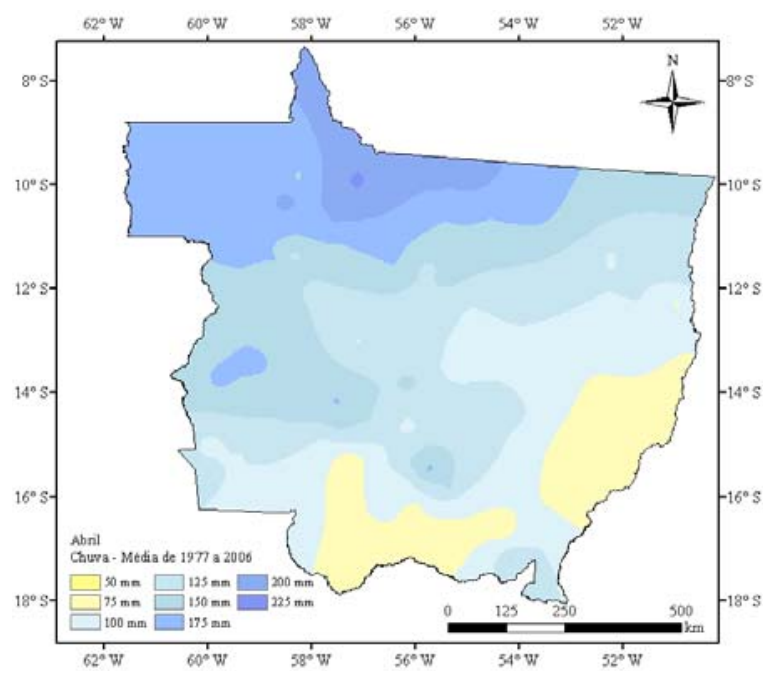

Figura 5 - Precipitação do mês de abril.

A Figura 6, referente ao mês de maio, corresponde ao início da estação seca em Mato Grosso, onde há uma diminuição significativa dos índices pluviais, variando de 18 a $81 \mathrm{~mm}$. Os maiores índices de precipitação, de 63 a $72 \mathrm{~mm}$, ocorreram no bioma Amazônico, concentrado a noroeste do estado. Os índices médios pluviais de $45 \mathrm{~mm}$ ocorreram no bioma pantanal e os índices menores, de 18 a 36 mm, no Cerrado. Observa-se assim, a inversão da pluviosidade entre os biomas cerrado e pantanal. Isto comparado com a estação chuvosa.

Os meses de junho, julho e agosto coincidem com o inverno no estado do Mato Grosso, que favorece as quedas de temperatura e estiagem. Rosa et al. (2007), coloca que nessa época, em Mato Grosso, as chuvas são raras, com precipitações de quatro a cinco dias, concentrando totais entre 20 e $80 \mathrm{~mm}$, como mostram as Figuras 7, 8 e 9. Ainda, o autor relata que as chuvas ocorrentes da estação de inverno são provenientes da ação frontal das massas de ar, proporcionadas pela passagem de frentes polares trazidas do sul pelo anticiclone polar (FK). Assim, as ocorrências de chuvas no extremo norte do estado de Mato Grosso são conseqüências do sistema de circulação perturbada de W (IT).

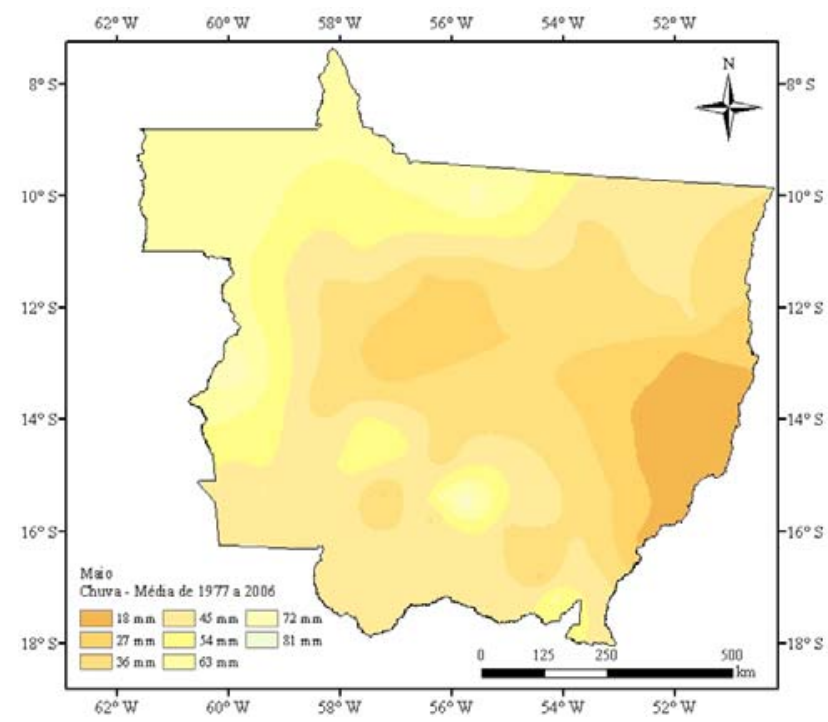

Figura 6 - Precipitação do mês de maio.

No mês de junho, visto na Figura 7, a precipitação pluviométrica teve uma variação de 0 a 30 $\mathrm{mm}$, onde o menor índice de precipitação $(0 \mathrm{~mm})$ localizou-se no extremo nordeste do estado, com pequenos epicentros distribuídos no bioma Cerrado. Os maiores índices de precipitação $(30 \mathrm{~mm})$ ocorreram no extremo noroeste e ao sudeste de mato Grosso.

O mês de julho é o mês mais seco do trimestre de análise - junho a agosto, com média de precipitação pluviométrica variando de 0 a $25 \mathrm{~mm}$. Sendo no bioma Cerrado e em boa parte do bioma Amazônia, onde ocorreram os menores índices, de 0 a 5 
mm. Já no bioma pantanal foram encontrados os maiores índices concentrados de chuvas, com valores de 15 a $20 \mathrm{~mm}$, como visto na Figura 8 . E valores de $25 \mathrm{~mm}$ se apresentaram na forma de epicentros pluviais distribuídas ao longo do território.

Observa-se que no mês de agosto, apresentado na Figura 9, os índices de pluviosidade acrescem de leste para oeste. Na porção leste concentram os menores índices pluviais, de 0 a $10 \mathrm{~mm}$, coincidindo com o bioma Cerrado, enquanto que os índices maiores se encontram ao oeste do estado.

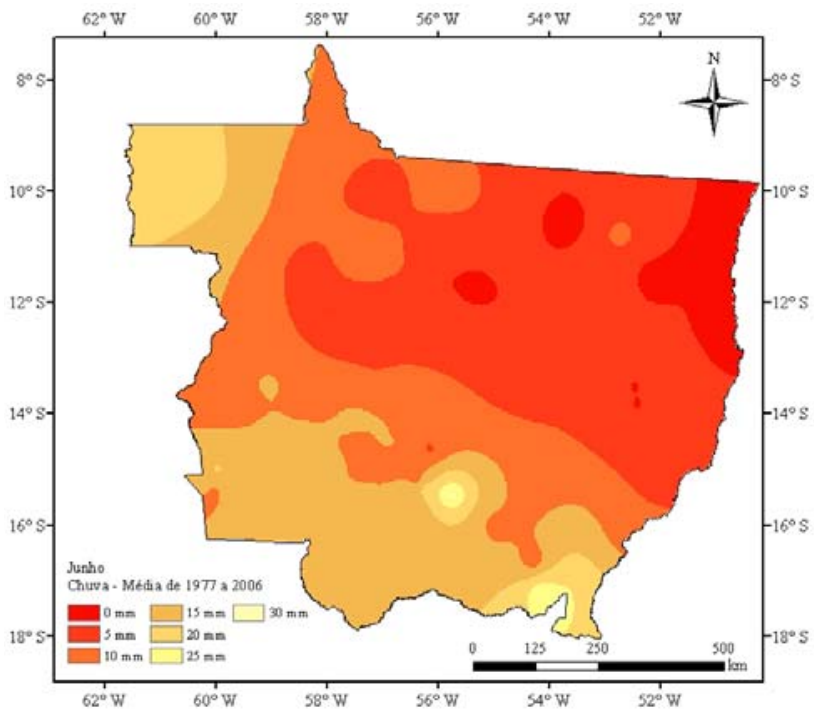

Figura 7 - Precipitação do mês de junho.

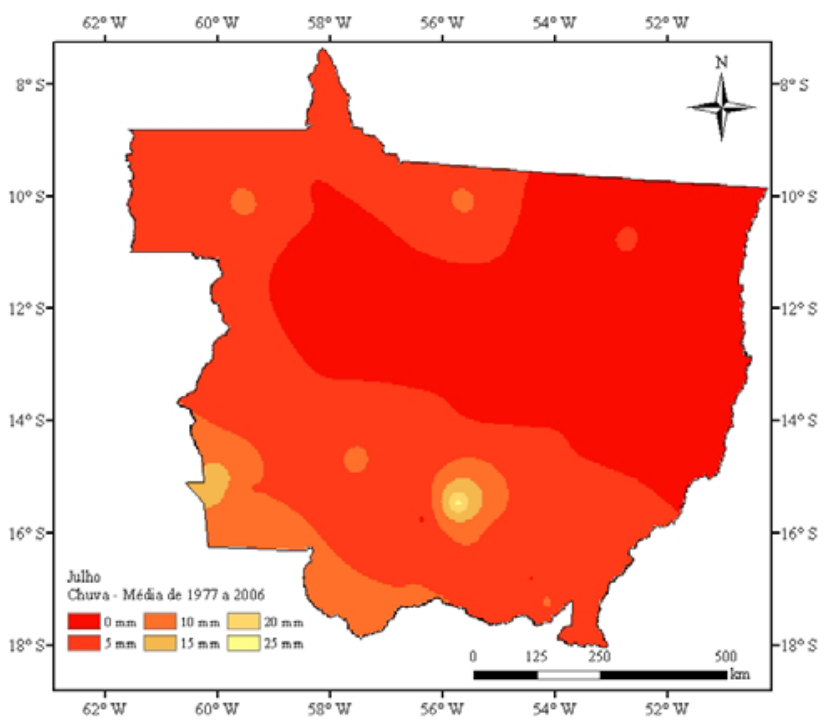

Figura 8 - Precipitação do mês de julho.

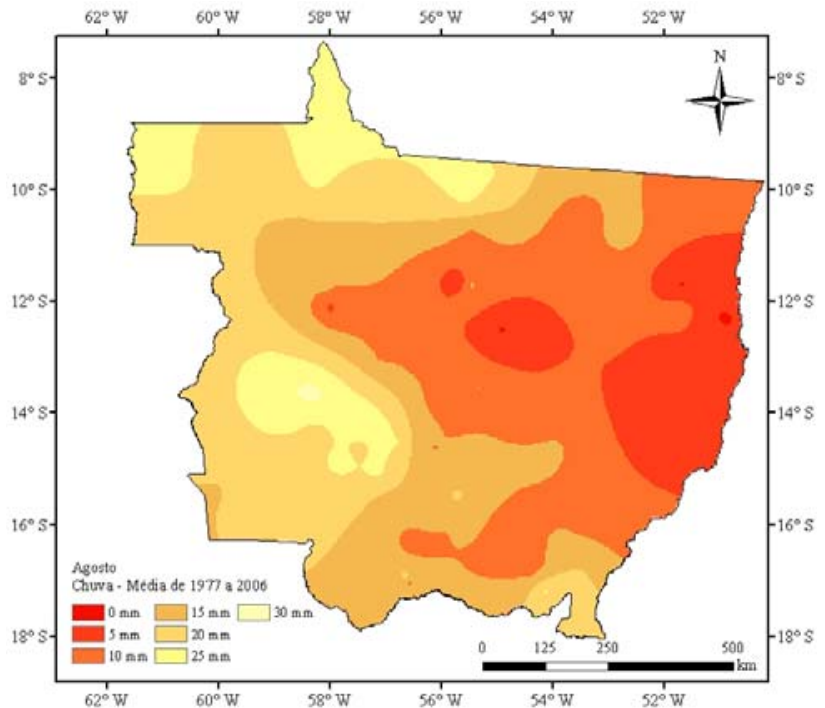

Figura 9 - Precipitação do mês de agosto.

O mês de setembro representa o período de transição da estação seca para a estação chuvosa, marcado pelo enfraquecimento da massa Polar Atlântica e o aumento da atuação da massa de ar Equatorial Continental. Na Figura 10 pode-se verificar o aumento significativo dos índices de precipitação, variando de 30 a $105 \mathrm{~mm}$. Os índices elevados de pluviosidade, com $105 \mathrm{~mm}$, localizaram-se ao norte do estado, no bioma Amazônico. Já nas porções central e sul ocorreram precipitações de valores médios, de 60 a $75 \mathrm{~mm}$.

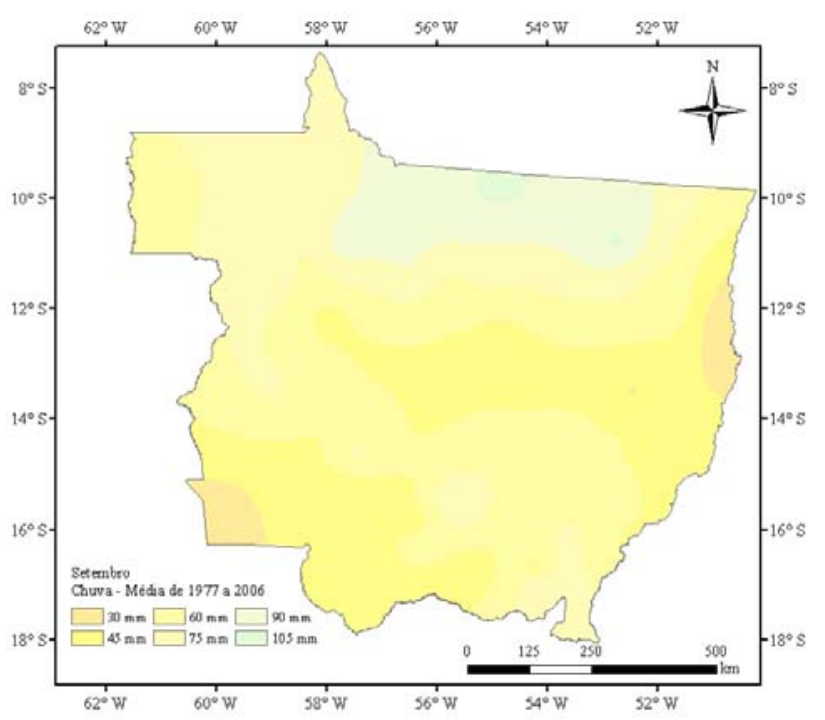

Figura 10 - Precipitação do mês de setembro. 
Segundo Rosa et al. (2007), o trimestre de setembro a novembro, é caracterizado por temperaturas altas, provenientes do aquecimento do equinócio da primavera. A principal característica desse período é a pouca ocorrência de precipitações, com o aumento gradativo do regime pluviométrico, sendo o máximo de chuva ocorrendo no final da primavera, coincidindo com o início do verão, no mês de dezembro. Podemos verificar tal fato nas Figuras 10,11 e 12 .

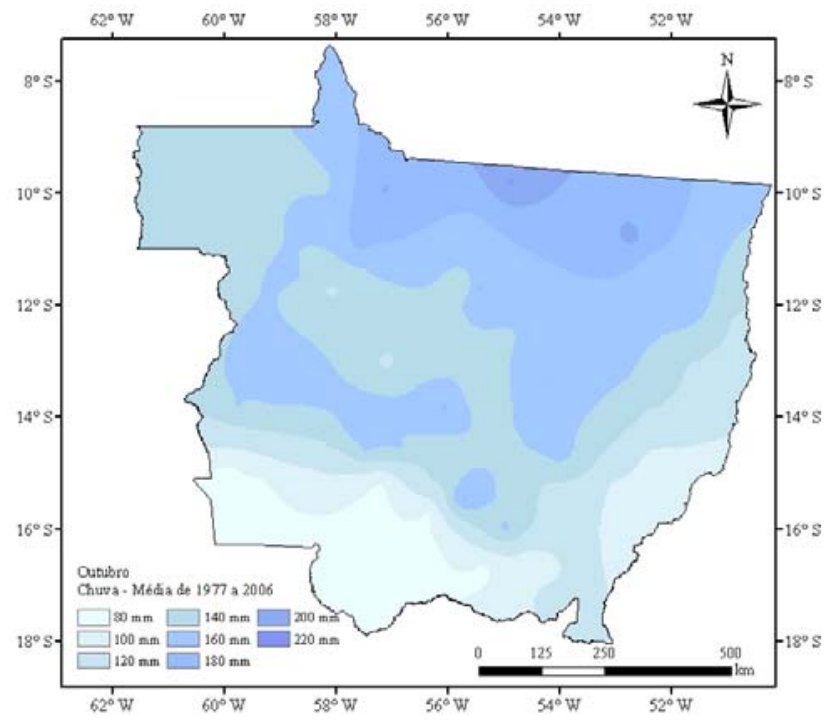

Figura 11 - Precipitação do mês de outubro.

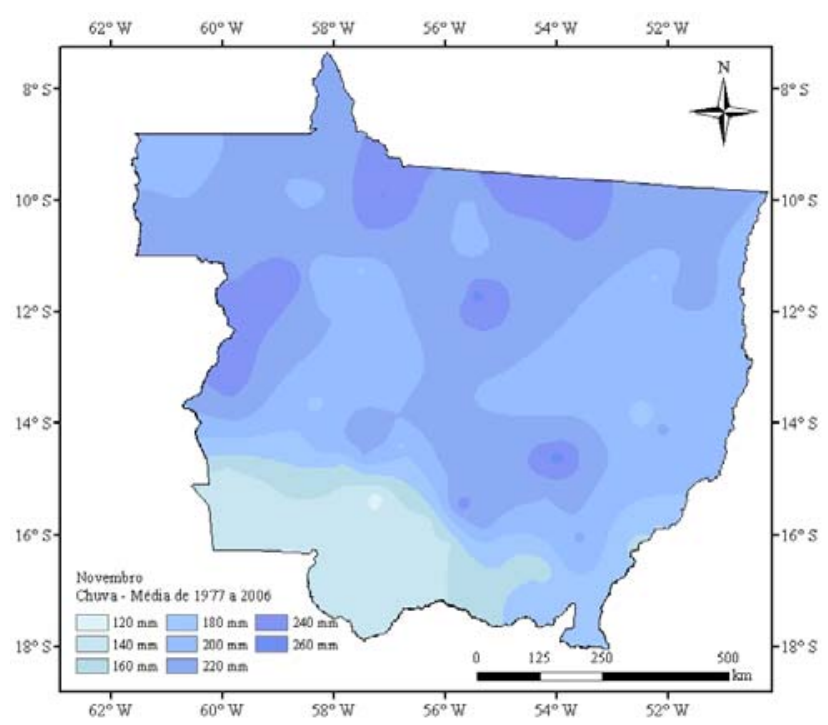

Figura 12 - Precipitação do mês de novembro.
O mês de dezembro compõe o período chuvoso do estado do Mato Grosso, junto com janeiro, fevereiro e março. Este mês apresentou comportamento pluvial similar aos demais dessa estação chuvosa, com os máximos de chuvas situados ao extremo norte e noroeste, no bioma amazônico e mínimos ao sul, no bioma do pantanal (Figura 13).

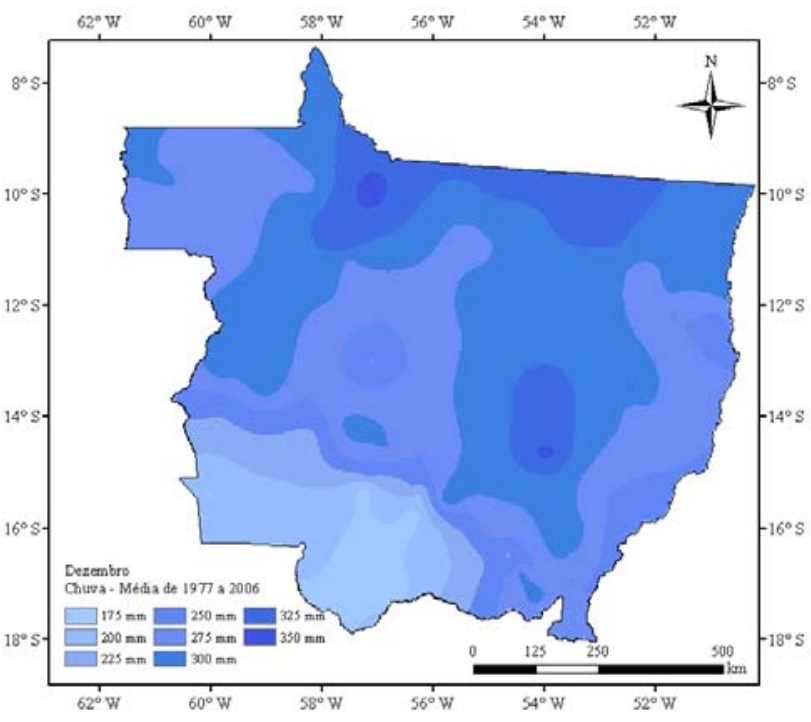

Figura 13 - Precipitação do mês de dezembro.

\section{Índice de Anomalia de chuva - IAC}

A utilização do IAC permitiu identificar padrões ou mudanças no comportamento da chuva, além de avaliar a distribuição espacial da mesma.. Assim com a aplicação dos IACs determinou-se os anos que se caracterizam como anos úmidos e anos secos.

As Figuras 14, 15 e 25, ilustram os IACs da estação do ano verão, referentes aos meses de janeiro, fevereiro e dezembro respectivamente, no estado, cuja característica é de alto índice de pluviosidade. Verifica-se na Figura 14 que o IAC do mês de janeiro teve 14 anos úmidos e 15 anos secos, com o ponto de maior inflexão dos anos úmidos ocorrendo no ano de 1979, caracterizado como muito chuvoso, por possuir um IAC maior que 2 e menor que 4 (Quadro 1), e o maior dos anos secos ocorreu em 1993, caracterizado como extremamente seco, apresentando o IAC menor que -4 (Quadro 1). O mês de fevereiro, Figura 15, teve 12 anos úmidos e 17 anos secos, sendo o maior IAC de anomalia de chuva, ocorreu em 1980, caracterizado como extremamente chuvoso, e o maior IAC dos anos secos, ocorreu 
no ano de 2001, sendo um ano muito seco (Quadro 1). Já o mês de dezembro ocorreram 14 anos úmidos e 15 anos secos, com o ponto de maior inflexão do período chuvoso foi no ano de 1978, caracterizando como muito chuvoso, e o maior ponto de inflexão dos anos secos foi no ano de 1985 , caracterizando como muito seco (Quadro 1).

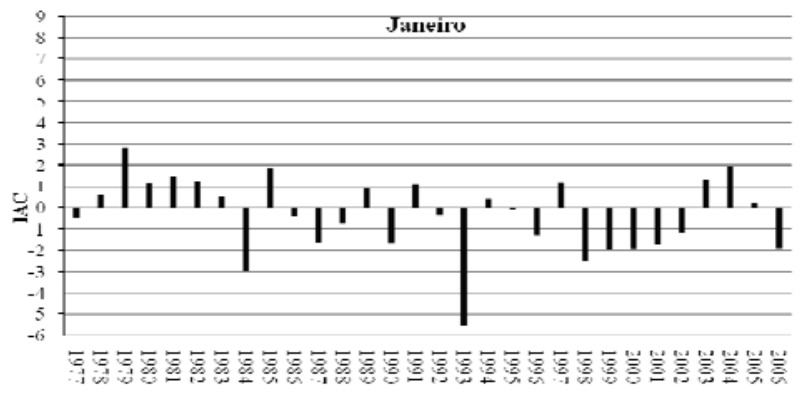

Figura 14 - Índice de Anomalia de chuva de janeiro

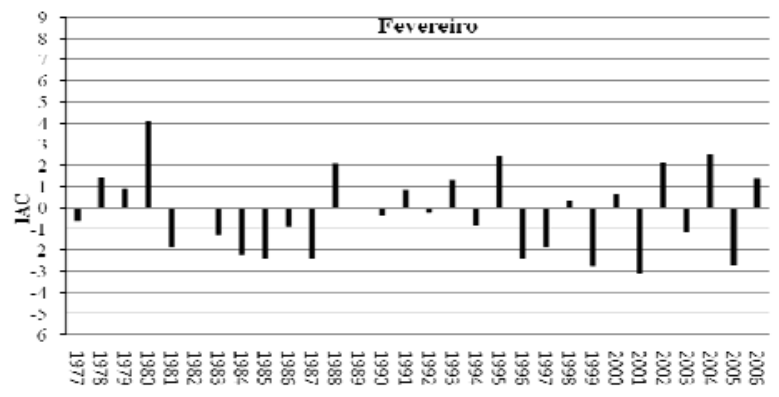

Figura 15 - Índice de Anomalia de chuva de fevereiro.

Os meses março, abril e maio, Figuras 16, 17 e 18, representam os IACs da estação do outono. Pode-se observa-se que o mês de março (Figura 16), teve 12 anos úmidos contra 18 anos secos, sendo o ano de 1991 de inflexão de maior umidade, classificado como muito chuvoso, e o maior IAC das anomalias secas ocorreu no ano 2004, classificado como muito seco (Quadro 1). No mês de abril (Figura 17) obteve 11 anos úmidos e 19 anos secos. Para o mês de maio, Figura 18, IAC indicou 13 anos úmidos e 16 anos secos. A maior anomalia úmida no mês de abril ocorreu no ano de 2006, classificado como muito chuvoso (Quadro 1), e a maior anomalia seca ocorreu no ano de 2002, classificada como muito seco. A maior anomalia úmida no mês de maio foi em 1995, classificada como extremamente chuvoso, e a maior anomalia seca, ocorreu no ano de 2000, sendo extremamente seco (Quadro 1).

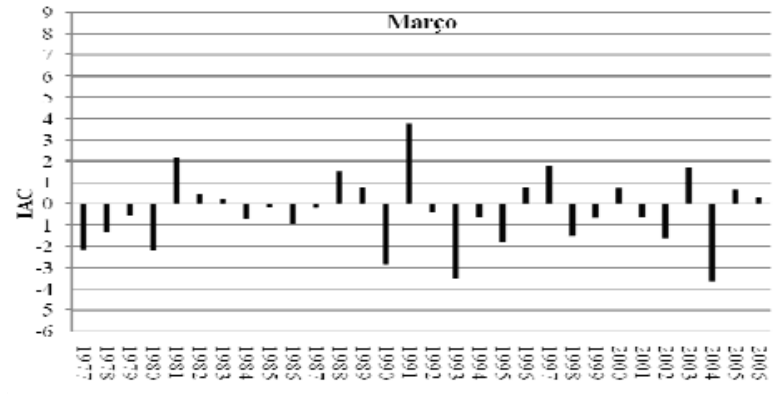

Figura 16 - Índice de Anomalia de Chuva de março.

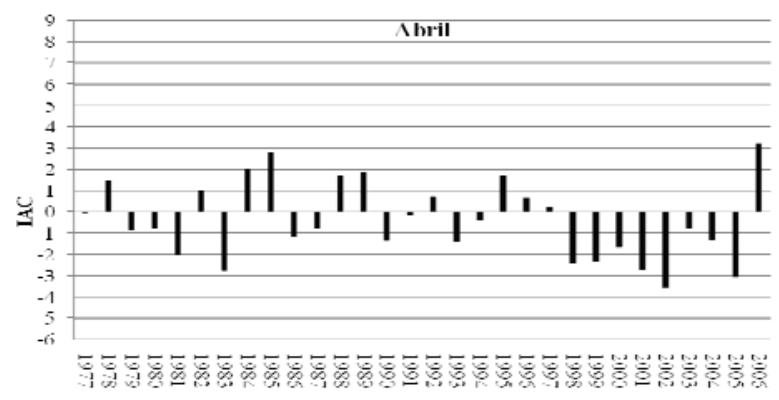

Figura 17 - Índice de Anomalia de Chuva de abril.

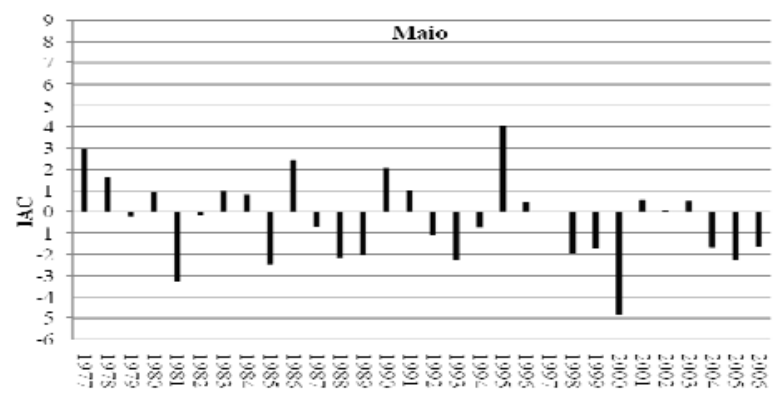

Figura 18 - Índice de Anomalia de Chuva de maio.

O trimestre representado pelos meses junho, julho e agosto, nas Figuras 19, 20 e 21 respectivamente, é a estação inverno em Mato Grosso, onde ocorreram 28 anos chuvosos e 60 anos secos. Nota-se na Figura 19, mês de junho, o IAC indicou que houve 8 anos úmidos e 21 anos secos, sendo a maior anomalia úmida ocorreu no ano de 1997, classificado como extremamente chuvoso (Quadro 1), e a maior anomalia seca ocorreu em 1998, classificada como muito seca (Quadro 1). No mês de julho (Figura 20) teve 10 anos úmidos contra 19 anos secos, onde o ano de 1978 ocorreu o maior índice de anomalia úmida e os anos de 1988, 1995 e 2003 fo- 
ram os maiores anos de anomalia de seca. Na Figura 21, verifica-se que o mês de agosto houve 10 anos úmidos e 20 anos secos, onde a maior anomalia úmida ocorreu no ano de 1986, classificado como extremante chuvoso (Quadro 1), e as maiores anomalias secas ocorreram nos anos de 1988 e 1991, classificadas como muito seco (Quadro 1).

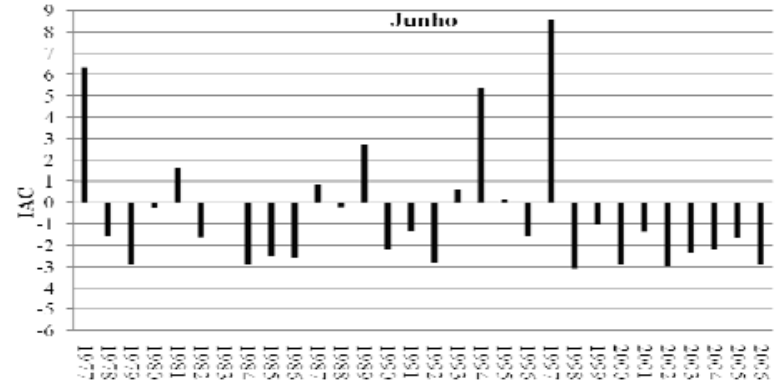

Figura 19 - Índice de Anomalia de Chuva de junho

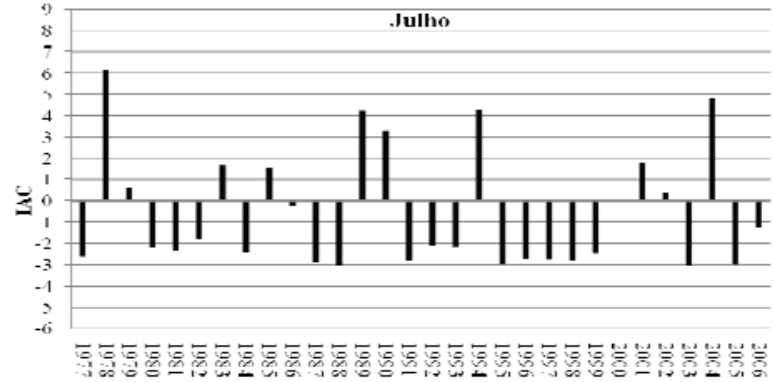

Figura 20 - Índice de Anomalia de Chuva de julho.

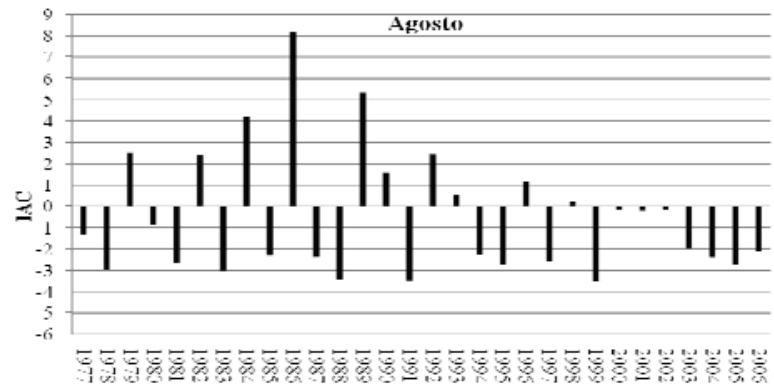

Figura 21 - Índice de Anomalia de Chuva de agosto.

O trimestre de setembro, outubro e novembro, mostrado nas Figuras 22, 23 e 24 é a estação primavera em Mato Grosso, que representa a passagem do período seco para o úmido e os IACs demonstram que ocorreram 31 anos chuvosos e 55 anos secos para esta estação. Verifica-se na Figura 22, que o IAC do mês de setembro houve 11 anos úmidos e 18 anos secos, com o ano de maior inflexão dos anos chuvosos ocorrendo em 1992, se caracterizando como extremamente chuvoso (Quadro 1), e o maior do anos secos em 1988, caracterizado como extremamente seco (Quadro 1). Para o mês de outubro o IAC indicou 11 anos úmidos, 18 anos secos, sendo a maior anomalia úmida foi no ano de 2006, classificado como muito chuvoso (Quadro 1) e maior anomalia seca ocorreu no ano de 1979. Já na Figura 24, mês de novembro, observa-se que o IAC apontou 9 anos úmidos, com o ano de 1996 de maior inflexão e 20 anomalias de anos secos, sendo o ano de 1989 a inflexão dos anos secos.

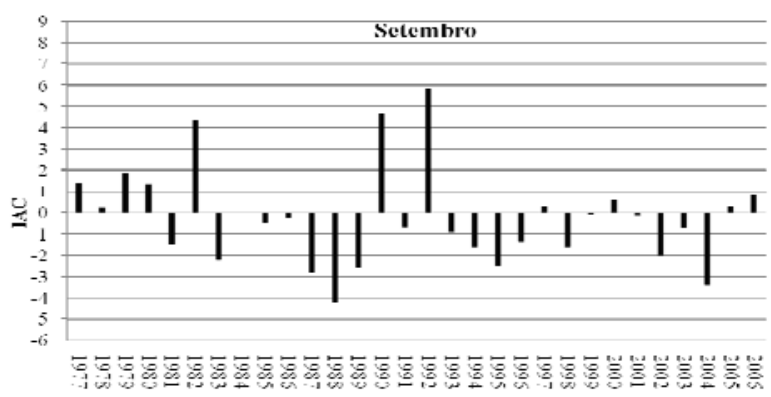

Figura 22 - Índice de Anomalia de Chuva de setembro.

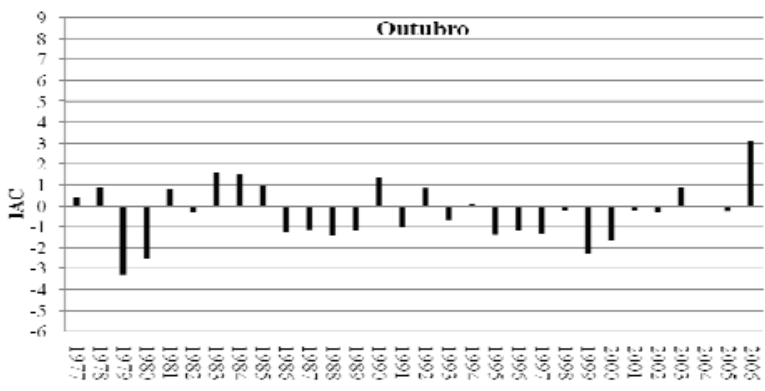

Figura 23 - Índice de Anomalia de Chuva de outubro.

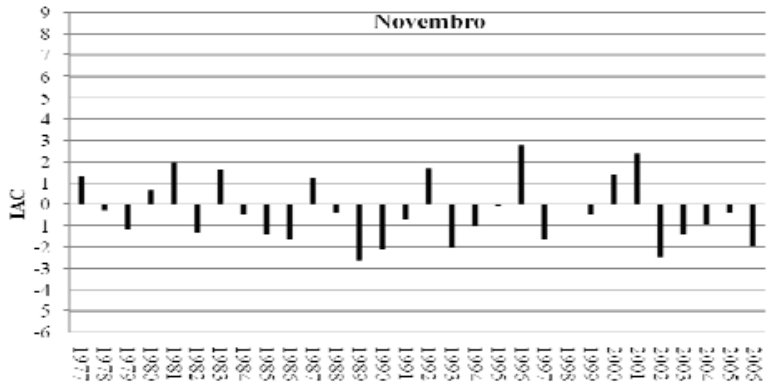

Figura 24 - Índice de Anomalia de Chuva de novembro. 


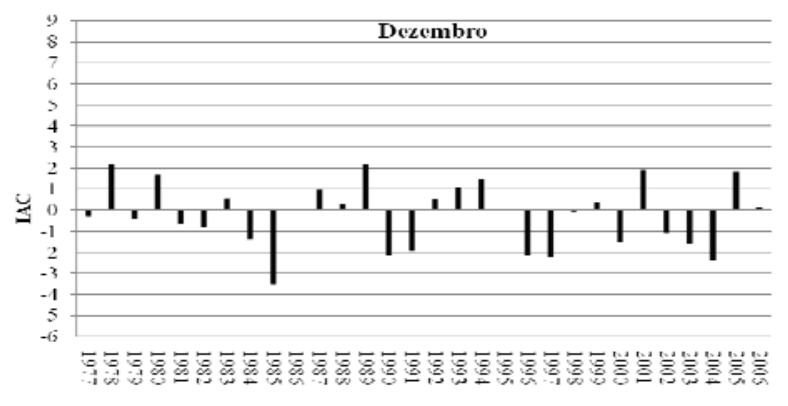

Figura 25 - Índice de Anomalia de Chuva de dezembro.

\section{CONGLUSÕES}

Neste trabalho, analisou-se a distribuição dos índices pluviométricos de maneira espacial e temporal, e estudou-se a sazonalidade utilizando o IAC, para a verificação dos períodos secos ou úmidos no estado do Mato Grosso.

$\mathrm{Na}$ análise das chuvas, comprovou-se, que os maiores índices pluviais concentraram na estação do ano primavera-verão, outubro a março, correspondendo a cerca de $86,5 \%$ do volume precipitado para média histórica de 1977 a 2006. Os menores índices de chuvas ocorreram no inverno, julho a agosto, correspondendo a 13,5\%. Já abril e setembro são meses que antecedem a mudança do comportamento hídrico em Mato Grosso.

A média pluviométrica anual também distribuiu de forma desigual ao longo do território matogrossense, separados por três grandes unidades fisiográficas, os biomas: Amazônico, Cerrado e Pantanal. Assim, observa-se que as maiores médias pluviais encontram-se no bioma Amazônico, localizado no extremo noroeste e norte, e os menores índices localizados no extremo sudoeste e sul, correspondentes com o bioma Pantanal.

$\mathrm{Na}$ aplicação do IAC para o período em analise, conclui-se que ocorreram mais eventos negativos, ou seja, anos secos.

Em decorrência dos resultados deste trabalho, evidencia-se a necessidade de mais estudos relacionados ao comportamento atmosférico, com ênfase à precipitação pluviométrica. Para corroborar com o planejamento e o zoneamento do estado do Mato Grosso, e melhor aproveitamento dos recursos naturais.

\section{AGRADECIMENTOS}

Os autores agradecem à CPRM/SGB (Companhia de Pesquisa de Recursos Minerais / Serviço Geológico do Brasil), à CAPES (PROEX) e ao CNPq - Brasil (processo 133866/2010-6), pelo auxílio que viabilizou o desenvolvimento deste trabalho.

\section{REFERÊNCIAS}

AGÊNCIA NACIONAL DE ÁGUAS. Brasília: ANA. Hidroweb. Disponível em: http://www.ana.gov.br. Acesso em: $11 / 12 / 2009$

ARAÚJO, L. E. ; MORAES NETO, J. M.; SOUSA, F. A. S. (2009). Classificação da precipitação anual e da quadra chuvosa da bacia do rio Paraíba utilizando índice de Anomalia de Chuva (IAC). Revista Ambiente \& Água - An Interdisciplinary Journal of Applied Science: v. 4, n. 3; p. 1-18.

BRAZ, R. L.; RIBEIRO, C. A.; FERREIRA, D. S.; CECÍLIO, R. A. (2009). Uso de séries históricas e técnicas de SIG no estudo da distribuição temporal e espacial da pluviosidade na Bacia Barra Seca localizada ao norte do estado do Espírito Santo. XI Encontro Latino Americano de Iniciação Científica e VII Encontro Latino Americano de Pós-Graduação - Universidade do Vale do Paraíba. Anais, v1, São José dos Campos SP. Disponível: http://www.inicepg.univap.br/cd/ INIC 2009/anais/; acessado em: 09/03/2010.

COUTININHO, A. C. (2005). Dinâmica das queimadas no estado do Mato Grosso e suas relações com as atividades antrópicas e a economia local. Tese (Doutorado em Ciência Ambiental) - Procam, Universidade de São Paulo; 308 p.

INSTITUTO BRASILEIRO DE GEOGRAFIA E ESTATÍSTICA. Brasília: IBGE (2009). Disponível em: http://www.ibge.gov.br/mapas ibge/

GAI, T. B.; BITAN, A.; MANES, A.; ALPERT, P.; RUBIN S. (1998). Spatial and Temporal Changes in Rainfall Frequency Distribution Patterns in Israel. Theoretical and Applied Climatology. 61; p. 177-190

NIMER, E. (1989). Climatologia do Brasil. Instituto Brasileiro de Geografia e Estatística, Rio de Janeiro, RJ; 421 p.

OLIVEIRA, J. R. T. (2007). Variabilidade pluviométrica decendial para a região sudeste do estado de Mato Grosso. I Simpósio de Recursos Hídricos do norte e centro-oeste. Anais, v1. Cuiabá-MT; p. 1-12.

ROSA, D. B.; SOUSA, R. R.; NASCIMENTO, L. A.; TOLEDO, L. G.; TOPANOTTI, D. Q.; NASCIMENTO, J. A. (2007). A distribuição espacial das chuvas na porção 
Centro oeste do estado de Mato Grosso-Brasil. Revista Eletrônica da Associação dos Geógrafos Brasileiros - Seção Três Lagoas. Três Lagoas - MS, v 1 n. 5; p. 127-152.

ROOY, M. P. VAN (1965). A Rainfall Anomaly Index Independent of Time and Space. Notes, 14, 43.

SILVA, J. W.; GUIMARÃES, E. C.; TAVERES, M. (2003). Variabilidade temporal da precipitação mensal e anual na estação climatológica de Uberaba-MG. Ciências Agrotecnologia. Lavras. v.27, n.3; p. 665674.

\title{
Space-Time Distribution of Rainfall Seasonality in the State of Mato Grosso
}

\begin{abstract}
Behavior analysis of rainfall is important because it allows detecting climate trends or changes on a regional or local scale. This study aimed to analyze spatial, temporal and seasonal rainfall variation in the state of Mato Grosso. We used data from 75 raingaging stations distributed throughout the state of Mato Grosso, with data for 30 years from 1977 to 2006. Rainfall maps were drawn with the aid of isohyets and applied to calculate the Rainfall Anomaly Index for the classification of dry and wet periods according to the local means organized as monthly, annual and seasonal temporal precipitation means. The interpolation method used was Raster Top, which utilizes the simple multi-grid method to minimize the equation in increasingly high resolutions, respecting the constraints of the physical elements that make up the landscape. The results show that rainfall distribution in the state of Mato Grosso has a wide variation of rates precipitated; the localities situated in the northwest and north have the highest rainfall values and places in the south of the state have the lowest rainfall. When the Rainfall Anomaly Index is applied for the period of study a larger number of dry years than wet years is shown.

Key-words: Rainfall, pluviometric, Rainfall Anomaly Index.
\end{abstract}

